\title{
Judicialização da política no Brasil: ver além do constitucionalismo liberal para ver melhor
}

\author{
Judicialization of politics in Brazil: looking beyond liberal \\ constitutionalism in order to see better
}

As análises acerca do Judiciário no Brasil e, especialmente, daquilo que se convencionou chamar de judicialização da política são hoje bastante variadas e em número suficiente para que se possa dizer que se conformou uma agenda de pesquisa minimamente consistente em torno da questão (Vianna et al., 1999; Carvalho Neto, 2004, 2007, 2008, 2009, 2010, 2013; Carvalho Neto e Tomio, 2013; Engelmann, 2003, 2004, 2007, 2008, 2011; Engelmann e Cunha, 2013; Nobre, 2008, 2011; Rodriguez, 2010a 2010b, 2013; Maciel e Koerner, 2002; Oliveira, 2005; Vianna, Salles e Burgos, 2007; Taylor e Da Ros, 2007). Essa agenda, no entanto, opera, fundamentalmente, a parir da tradição libe$\mathrm{ral}^{1}$, tanto no campo do constitucionalismo quanto no da teoria democrática.

\footnotetext{
É professor titular do Departamento de Ciência Política da Universidade Federal de Minas Gerais (Belo Horizonte, MG). E-mail: avritzer1@gmail.com.

** É professora adjunta do Departamento de Ciência Política da Universidade Federal de Minas Gerais (Belo Horizonte, MG) e pesquisadora do Centro de Estudos Social da América Latina (CESAL). E-mail: maronamarjorie@gmail.com.

São muitos os autores e inúmeras as contribuições teóricas que podem ser situados no campo do liberalismo. Entre os liberais clássicos, frequentemente são invocados os nomes de John Locke, Montesquieu, Kant, Adam Smith, Benjamin Constant, Madison, Tocqueville, Mill, entre outros. Contemporaneamente, é possível identificar pelo menos duas vertentes teóricas do liberalismo: o libertarianismo, associado a Friedrich Von Hayek e Robert Nozick; e o liberalismo igualitário, vinculado especialmente a John Rawls, mas também, a Ronald Dworkin, Brian Barry, Thomas Nagel, Joshua Cohen, Philippe Van Parijs e outros. Não obstante os inúmeros contrastes e variadas nuances que possam ser apontadas no interior da tradição liberal, pelo menos duas convergências a atravessam: o individualismo ético (que envolve uma peculiar percepção acerca da constituição do self) e a neutralidade (de justificação) do Estado. É nessa perspectiva que aqui será tratada a questão. Para mais: Ostrensky (2013, p. 47-54); Vita (2013, p. 55-65); Costa e Werle (2000, p. 47-66).
} 
No entanto, existem motivos suficientes para questionar essa referência analítica para o caso do Brasil. Sob esse pressuposto, o trabalho soma-se ao conjunto de análises acerca das relações entre direito, política e Judiciário no Brasil, mas visa a abordar a questão a partir de uma nova perspectiva analítica que permita avançar as reflexões no campo.

Argumenta-se que, embora não haja propriamente um consenso acerca do que expressa a judicialização da política no Brasil, ou de quais as suas consequências para o sistema político e para o regime democrático, as narrativas acerca do fenômeno são construídas a partir de uma perspectiva teórica comum, forjada sob os auspícios da tradição liberal no campo do constitucionalismo e da teoria democrática. A adoção de uma perspectiva analítica que supere o marco liberal permite que se avancem as reflexões acerca da judicialização da política, renovando os termos do debate pela compreensão mais aprofundada do papel do Judiciário na conformação da cidadania no Brasil. Eis a contribuição que pretendemos oferecer com este trabalho.

O texto está divido em três partes, além de uma introdução e de uma conclusão. Na primeira parte buscamos reconstruir a concepção clássica do constitucionalismo, tal qual forjada a partir das lições retiradas da revolução norte-americana e contribuições das doutrinas e experiências europeias no campo, no âmbito de uma segunda onda de constitucionalização dos regimes democráticos (Hirschl, 2009). Buscamos, então, na segunda parte do texto, empreender um esforço de (re)construção crítica do constitucionalismo e da teoria da representação, articulando algumas das contribuições de teóricos do reconhecimento (Honneth, 2003; Fraser, 2008) sob o pano de fundo das recentes experiências de refundação democrática de diversos estados na América Latina (Ferrajoli, 2007; Gargarella e Courtis, 2009; Gargarella, 2013; Grijalva, 2008; Santos, 2010; Sieder, 2002; Tapia, 2007; Viciano Pastor e Martinez Dalmau, 2005, 2010; Yrigoyen Fajardo, 2006, 2009). O tema da judicialização da política, entretanto, será tratado mais especificamente na terceira parte deste trabalho, na qual se articula a tese que guia nossos esforços, de que a superação da perspectiva analítica liberal do fenômeno permite aproximar o fenômeno das lutas de cidadania, especialmente em contextos de desigualdade social e diversidade cultural, tal qual o brasileiro. 


\section{Constitucionalismo e democracia: lições clássicas}

A tradição liberal relaciona o constitucionalismo à estabilidade. Nesses termos, o constitucionalismo expressa aquele conjunto de regras elaborado contra a discricionariedade, a negociação de interesses, que é típica da política. A pressuposição óbvia é a que opõe o reino da política, das paixões, dos particularismos, ao do direito, da razão, dos princípios. Uma das funções mais importantes daqueles limites de inspiração constitucional é, portanto, constituir obstáculos à construção de decisões majoritárias futuras (Elster e Slagstadt, 1988). Se bem que essa perspectiva representa a vertente utilitarista do liberalismo constitucional, a qual assume uma tensão irreconciliável entre constitucionalismo e democracia. A vertente do igualitarismo, por outro lado, toma o constitucionalismo como condição de possibilidade da democracia e aproxima-se da segunda onda de constitucionalização dos regimes democráticos, especialmente fundada na experiência europeia de fortalecimento e ampliação do catálogo de direitos fundamentais. Nesses termos pode ser compreendido Ronald Dworkin (2001, 2007, 2010), para quem o constitucionalismo opera como fundamento moral da ordem jurídica, mas também Ely (1980), para quem os freios constitucionais, longe de serem antidemocráticos, podem reforçar a democracia.

A disputa acerca da relação entre constitucionalismo e democracia pode retroceder, pelo menos, até o século XVIII e está intimamente ligada às posições assumidas pelos Federalistas diante dos desafios que lhes impunha a Revolução Americana ${ }^{2}$. Esse processo foi marcado por dois momentos: um primeiro, fortemente soberano, que levou à constituição dos artigos da Federação e que reforçou a soberania local; e um segundo, em que se coloca a necessidade de fortalecimento do governo central.

\footnotetext{
O movimento político institucional conhecido como Revolução Americana possui especificidades que tornam único o emprego do termo revolução nesse contexto (Arendt, 1965). Na tradição do pensamento político, as revoluções são conhecidas como rupturas violentas da ordem política que anulam a forma de governo existente e instauram um princípio substantivo de organização, seja ele liberdade, igualdade e solidariedade, seja ele o governo da classe trabalhadora. Esse foi o caso das Revoluções Francesa e Russa, que consagraram o uso do termo "revolução" no pensamento político. Diferentemente dessa tradição, porém, o movimento político conhecido como Revolução Americana não implicou a destruição de uma forma de governo, mas, antes, a consolidação de uma tradição de horizontalidade e de soberania nas relações políticas que tem origem nas práticas políticas introduzidas em algumas das 13 colônias, em particular naquelas localizadas na Nova Inglaterra, durante os cem anos anteriores. Eis, portanto, o sentido que o termo "revolução" tem nesse episódio histórico particular.
} 
No âmbito da discussão original que envolve o processo de independência em face da Coroa Inglesa (Rehfeld, 2005) acerca de como manter uma tradição de forte identidade e soberania no nível local, conformou-se uma tradição de radicalismo democrático, com governos locais fortes e um governo central débil, que entrou em crise ainda na sua primeira década, devido à sua fragilidade econômica e política. Daí é que, em um segundo momento, coloca-se a necessidade de uma nova convenção constitucional para formar um governo nacional que tivesse capacidade de formulação de uma agenda política para o país como um todo ${ }^{3}$.

Entretanto, o processo de formação de uma Constituição e de um governo nacional nos Estados Unidos foi muito menos consensual do que alguns autores apontam. A convenção constitucional se organizou sobre a sombra de diferentes concepções de constitucionalismo ${ }^{4}$, tendo vindo a prevalecer aquela defendida pelos Federalistas, em contornos emprestados por Madison, para quem o majoritarianismo de uma geração não constitui elemento suficiente para a revisão constitucional, sendo útil, ademais, para as gerações futuras que estejam pré-comprometidas com um certo arranjo constitucional (Holmes, 1988).

$\mathrm{O}$ arcabouço madisoniano não só dificulta ao extremo o processo de revisão constitucional como também justifica as limitações impostas pela Constituição, pela pressuposição de que o pluralismo expressa antes uma ameaça do que uma possibilidade de construção política ${ }^{5}$. Esse arcabouço teórico, que se tornou central no processo de elaboração constitucional norte-americano, supõe que é improdutivo e frequentemente conflituoso

Como afirmou Madison em carta a Thomas Jefferson: "É objeto de concordância geral que a União não pode ser assegurada no princípio da confederação de estados soberanos. Uma observação voluntária da legislação federal pelos estados não será nunca alcançada" (Ackerman, 1993, p. 193).

4 Vale a pena mencionar a concepção defendida por Paine, para quem a Constituição representava um "consenso dos vivos", de modo que, em repúblicas democráticas, segundo o autor, o presente não deve estar fundado no passado, senão que deve ser determinado pela opinião dos vivos. Também é digna de nota a concepção de Jefferson, que sustentava a necessidade de uma carta de direitos e defendia a ideia de que a forma de governo poderia estar além da vontade de gerações específicas, mas a Constituição deveria responder à vontade das diferentes gerações, de modo que a ideia de perpetuação da vontade política seria moralmente repugnante.

Madison lança essa ideia com bastante clareza no assim chamado Federalista número 10, em que afirma que "a capacidade desigual de adquirir propriedades" e as "diferentes opiniões relativas à religião e ao governo" supõem uma pluralidade que pode levar os indivíduos a tentar oprimir uns aos outros. O pluralismo, na versão que the empresta Madison, não serve de pressuposto argumentativo para o desenvolvimento de uma teoria do governo, senão que reforça a ideia da Constituição como pré-comprometimento das diversas gerações. 
permitir a revisão permanente daqueles elementos consensuais na área dos direitos fundamentais e do governo, estabelecidos pelas gerações anteriores como fatores limitadores da democracia. Nesses termos, o sistema político americano conformou-se por um governo nacional forte, mas apenas nas questões não resguardadas pelo próprio constitucionalismo.

Duas consequências principais se seguiram à consolidação da ideia da Constituição como a expressão de um pré-comprometimento geracional. A primeira delas foi o estabelecimento de um sistema muito rígido de revisão constitucional, o que fez com que a Constituição norte-americana fosse pouquíssimo emendada nos últimos duzentos anos ${ }^{6}$. A segunda consequência é, propriamente, o estabelecimento de um processo de adequação constitucional da legislação ordinária, em face da relação de subordinação que aquela ideia de Constituição impõe.

A possibilidade de revisão judicial da constitucionalidade das leis ( judicial review), embora remeta aos debates entre os Federalistas, se consolidou, de fato, nos Estados Unidos da América, nos primeiros anos do século XIX, durante a gestão de Marshall na Suprema Corte como consequência direta do conhecido caso Marbury versus Madison? ${ }^{7}$

Nesses termos, a experiência constitucional norte-americana nos lega um constitucionalismo ancorado na específica natureza da Constituição como um pré-comprometimento geracional que impõe um modelo de "soberania autoextinguível”. Isto é, a quase imutabilidade do texto constitucional, associada à possibilidade de declaração de inconstitucionalidade da legislação ordinária e dos atos normativos do governo, pela via do judicial review, delineia um povo que é soberano para elaborar a Constituição, mas deixa de sê-lo no momento em que ela é promulgada.

Essa, contudo, é uma das interpretações possíveis acerca do modo como se conformou o constitucionalismo norte-americano, que não leva em conta, entretanto, um segundo momento do processo de formação do sistema político nos Estados Unidos, representado pela Guerra de Secessão, sem o qual não é possível entender os resultados da Revolução Americana. A

A Constituição norte-americana sofreu, em sua existência, vinte emendas, o que estabelece uma média de uma emenda a cada onze anos.

Nesse caso, relatado pelo próprio Marshall, a petição de William Marbury foi negada pela Suprema Corte, que considerou o estatuto no qual ele se baseava inconstitucional. Esse foi o primeiro caso no qual uma ação julgada pela Suprema Corte declarou inconstitucional um ato normativo e com isso estabeleceu um princípio de revisão dos atos do governo pelo Poder Judiciário (Ely, 1980, p. 8). 
Guerra de Secessão constitui um episódio claro de crise constitucional, tanto da perspectiva da relação entre os poderes quanto da perspectiva da relação entre o governo nacional e os estados.

Designadamente, a decisão da Suprema Corte dos Estados Unidos, conhecida como Dred-Scott ${ }^{8}$, expressa todos os problemas da soberania limitada, a efetivação mais problemática do modelo oriundo da Revolução Americana e, não por acaso, é considerada um fator precipitador da Guerra Civil nos Estados Unidos, ao final da qual foi promulgada a Emenda 14, sem a qual não é possível interpretar plenamente a Revolução Americana e o constitucionalismo nos Estados Unidos. De fato, a Emenda 14, que consagrou a cláusula da equal protection of law (igualdade perante a lei), decreta que todas as pessoas nascidas nos Estados Unidos são cidadãos do país, possuem imunidade e não podem perder sua liberdade sem o devido processo legal ${ }^{9}$. Assim, não só as legislações estaduais anteriores são declaradas nulas como também as precedentes decisões da Suprema Corte - em particular aquela conhecida como Dred-Scott.

Não é possível entender o processo de formação constitucional norte-americana sem considerar esse particular momento, a partir do qual se ampliou a cidadania nos Estados Unidos, pela generalização da igualdade formal (perante a lei). A perspectiva dualista defendida por Bruce Ackerman (1988), segundo a qual tanto as gerações passadas quanto as gerações presentes têm direito à palavra no arranjo constitucional norte-americano, só faz sentido em um contexto no qual a cidadania liberal - pelo menos os seus elementos civil e político - se generaliza ${ }^{10}$.

\footnotetext{
No âmbito desse processo a Suprema Corte impõe contra a soberania popular dois fatos: nega o pedido do demandante de origem negra de ter liberdade em estados onde não havia escravidão - refutando, portanto, a ideia de que indivíduos da raça negra tivessem direitos de cidadania assegurados em todo o território nacional; e declara inconstitucional a legislação do Congresso, conhecida como Missouri Compromise, que diferenciava estados escravocratas e não escravocratas.

9 Segundo a Cláusula da Igual Proteção perante a Lei: "Todas as pessoas nascidas ou naturalizadas nos Estados Unidos e sujeitas a sua jurisdição são cidadãos dos Estados Unidos e do Estado onde tiver residência. Nenhum Estado poderá fazer ou executar leis restringindo os privilégios ou as imunidades dos cidadãos dos Estados Unidos, nem poderá privar qualquer pessoa de sua vida, liberdade ou bens sem o devido processo legal, ou negar a qualquer pessoa sob sua jurisdição igual proteção das leis" (tradução nossa).

${ }^{10}$ De acordo com Marshall (1967), a participação integral na comunidade, que a cidadania liberal indica, se constitui de um elemento civil, composto por direitos necessários à liberdade individual (de ir e vir, de manifestação do pensamento e da fé, de imprensa, à propriedade privada, o de concluir contratos válidos e o direito à justiça, que se traduz na possibilidade de afirmar todos os anteriores, em condições de igualdade recíproca, assegurada pelas instituições judiciárias). O elemento político da cidadania,
} 
Isso porque, quando a Suprema Corte declara uma lei ou ato normativo inconstitucional, segundo Ackerman (1988, p. 192), o que ela faz na verdade é chamar a atenção dos indivíduos privados para o fato de que uma nova questão está posta para aquela geração e que cabe a ela redefinir os contornos da comunidade política, o que pressupõe, evidentemente, a generalização da cidadania, o seu elemento político. O judicial review, que, nesses termos, expressa uma oportunidade de renovação dos contornos da comunidade política, opera no âmbito de um sistema no qual a Suprema Corte atua em maior ou menor articulação com os demais órgãos do próprio Judiciário.

É preciso atentar para o fato, portanto, de que no modelo americano de revisão judicial das leis e atos normativos não há a possibilidade de ações diretas questionarem abstratamente a constitucionalidade das normas jurídicas. Conforma-se, assim, uma revisão judicial de tipo difusa. Isto é, todos os órgãos do Judiciário têm competência para analisar o caso concreto à luz da Constituição, mas os efeitos da decisão estão circunscritos às partes litigantes. A Suprema Corte só participa do processo de revisão judicial pela via recursal e após o controle de admissibilidade (Rule of Four), no qual quatro dos nove juízes aprovam o writ of certiorari, o que implica a recolha de informações acerca do caso concreto sob judice para posterior revisão. A Suprema Corte não tem, portanto, o monopólio da interpretação sobre a Constituição, dividindo tal prerrogativa com os demais órgãos do Judiciário (Arantes, 2013).

A experiência precursora de constitucionalização dos regimes democráticos liberais foi, sem dúvida, aquela que se confunde com a história de formação dos Estados Unidos da América, mas o processo de constitucionalização das democracias contemporâneas envolve posteriores ciclos de expansão (Hirschl, 2009), dos quais interessa, nesse ponto, aquele que ocorreu durante a reconstrução dos países derrotados na Segunda Guerra (Japão, Itália e Alemanha), porque nos legou um modelo de controle de constitucionalidade das leis que permite que se estabeleça um diálogo consistente, no campo dos

por sua vez, se relaciona com o direito de participar do poder, seja como membro de um organismo investido de autoridade política ou como eleitor de seus membros. Os direitos civis, como elementos da cidadania, vão ser assegurados ao longo do século XVIII, em larga medida em razão da atuação dos tribunais pela afirmação da universalidade da condição de liberdade individual. O período de formação dos direitos políticos, por outro lado, remete ao século XIX, quando os direitos civis, ligados ao status de liberdade, já haviam reunido consistência suficiente para que a ideia de cidadania ganhasse contornos de universalidade. Por fim, o elemento social da cidadania moderna, conformado ao longo do século XX, remete à compreensão de que um mínimo de segurança econômica e bem-estar social é pressuposto do exercício da cidadania. 
direitos, capaz de avançar reflexões acerca do acesso à justiça ou das lutas de cidadania, especialmente em face de sociedades marcadas por diferenciações em termos de classe. Nesse ponto é, de fato, útil reconhecer a influência dos debates em torno da constitucionalização da vida política, que se desenrola na Europa, em meados do século XX. O primeiro tribunal constitucional em território europeu foi previsto pela Constituição austríaca de 1920, por obra e influência de Hans Kelsen, tendo gerado enorme polêmica no continente.

Na melhor tradição liberal, invoca-se o clássico esquema de Marshall ${ }^{11}$ (1967) na pressuposição de que o exercício satisfatório dos direitos políticos só é possível na vigência plena dos direitos civis e liberdades e autonomia pessoal. A ênfase nos direitos fundamentais (ou de cidadania) permite que se reavalie a anunciada tensão irreconciliável entre constitucionalismo e democracia, recolocando-o como condição de possibilidade da democracia. É que a identificação entre o cidadão e o sujeito de direito redunda no fato de que a possibilidade de "ser membro com igual valor de uma coletividade política” (Honneth, 2003, p. 190) depende da adjudicação daqueles direitos fundamentais, os quais assumem a função de proteger a posse e o exercício da imputabilidade moral, da autonomia privada, da liberdade individual.

Daí que a discussão em torno do fenômeno aproxima-se definitivamente dos embates em torno das lutas de cidadania (e do acesso à justiça), em pelo menos dois aspectos. Em primeiro lugar, porque se exige efetividade das instituições judiciais, especialmente do Poder Judiciário, na reversão do quadro de ineficácia da lei e de recorrentes violações de muitos direitos básicos, o que exclui da cidadania civil um conjunto alargado da população, pressupondo, aliás, que mesmo a desigualdade socioeconômica afeta o desempenho da democracia. Em segundo lugar porque, pela via do controle de constitucionalidade das leis, o Poder Judiciário e, especialmente, as Cortes

\footnotetext{
De acordo com Marshall, a participação integral na comunidade, que a cidadania moderna indica, se constitui de um elemento civil, em político e um social. O elemento civil é composto por direitos necessários à liberdade individual (de ir e vir, de manifestação do pensamento e da fé, de imprensa, à propriedade privada, o de concluir contratos válidos e o direito à justiça, que se traduz na possibilidade de afirmar todos os anteriores, em condições de igualdade recíproca, assegura pelas instituições judiciárias) e vieram a ser assegurados ao longo do século XVIII. O elemento político da cidadania, por sua vez, se relaciona com o direito de participar do poder remete a lutas sociais travadas ao longo do século XIX pela democratização dos estados liberais. Por fim, o elemento social da cidadania moderna, conformado ao longo do século XX, remete à compreensão de que um mínimo de segurança econômica e bem-estar social é pressuposto do exercício da cidadania.
} 
Constitucionais, oferecem interpretações acerca do direito que afetam o escopo da cidadania, embora não alterem os seus parâmetros.

Em ambas as versões, contudo, a tradição liberal assume aquela descrição sobre a formação dos estados modernos, cujo elemento central é o contrato social - contida na ideia de que a ordem constitucional é contratada entre indivíduos livres e iguais - e, com isso, uma concepção de cidadania que ganha contornos universalistas e individualistas. $\mathrm{O}$ cidadão (universal) é o sujeito de direitos, a pessoa portadora de direitos efetivos na esfera civil das relações interindividuais e também das relações dos indivíduos com o Estado (Reis e O’Donnell, 1988). A consagração constitucional dos direitos sociais e econômicos, vinculada à vertente igualitária do constitucionalismo, acrescentou às propriedades que colocam um sujeito em condições de agir autonomamente uma medida mínima de formação cultural e de segurança econômica, mas não complexificou a cidadania, mantendo sua base individualista e universalista de Constituição.

\section{Constitucionalismo e democracia no Brasil pós-88: entre as lições clássicas e as novidades regionais}

O processo de independência da grande maioria dos países latino-americanos, ao longo do século XIX, deu continuidade àquela tradição constitucional clássica estabelecida na América do Norte e Europa (Gargarella, 2013; Avritzer, 2012), mas com resultados bastante diferentes. Se, por um lado, a América Latina jamais subverteu os princípios do liberalismo e da divisão dos poderes com pesos e contrapesos, por outro, rupturas constitucionais foram comuns na região. Mais recentemente, uma nova onda de reformas constitucionais emergiu - especialmente pelo reconhecimento das especificidades históricas do continente ${ }^{12}$ e o declínio de regimes autoritários na América Latina -, resultando na adjudicação de novos contornos ao constitucionalismo regional.

De acordo com Gargarella (2013), na segunda metade do século XIX desenhou-se um constitucionalismo de fusão na América Latina, a partir de um pacto liberal-conservador, que se estendeu tanto à área da organização

12 Os estados nacionais latino-americanos se formaram a partir das lutas pela independência protagonizadas, na maioria das vezes, por elites locais descendentes de europeus, que, afirmando defender princípios universais, acabaram por relegar povos originários e os imigrantes forçados africanos à condição de "subcidadania". Nas ex-colônias, altamente racializadas, a equalização jurídico-constitucional não garantiu a igualdade efetiva, o que se tornou evidente na discrepância entre a nação (cívica) que emergiu das Constituições e as nações (etnogeográficas) existentes no território (Mendonça e Marona, 2014). 
do poder quanto à dos direitos ${ }^{13}$, resultando em um generalizado rechaço à tradição política republicana e um olhar restritivo sobre os direitos políticos. Um século mais tarde, apenas, a questão social teria assumido centralidade na agenda política e acabaria por ser anexada àquela velha matriz liberal-conservadora, produzindo Constituições mais atentas aos direitos sociais, embora conservadoras e centralizadoras no que concerne à organização do poder.

Ao final do século XX novas e profundas mudanças na região, induzidas pela generalizada crise política e de direitos humanos, derivada das ditaduras que assolaram a América Latina ao longo dos anos 1970, impulsionariam a reflexão crítica acerca do sistema de autoridade concentrado na figura do Executivo. Ademais, a crise neoliberal demandaria que se renovasse a reflexão acerca das implicações e responsabilidades econômicas do Estado. Por fim, a proliferação de lutas sociais complementaria o cenário turbulento (Viciano Pastor e Martinez Dalmau, 2005, 2010) no âmbito do qual um amplo processo de reconstitucionalização dos estados latino-americanos culminou com a promulgação das Constituições do Brasil (1988), Colômbia (1991), Paraguai (1992), Peru (1993), Venezuela (1999), Equador (2008) e Bolívia (2009).

É possível a identificação de três ciclos de reforma, os quais revelam a passagem de uma disposição para o reconhecimento dos direitos de minorias (Brasil, 1988) para a admissão da identidade multicultural e do pluralismo social, político e jurídico dos estados latino-americanos (Colômbia, 1991), até o enfrentamento do caráter unitário da nação com a formulação do conceito de Estado Plurinacional (Equador, 2008; Bolívia, 2009) (Yrigoyen Fajardo, 2006, 2009). Essas experiências, que são bastante diversas entre si,

\footnotetext{
3 Para melhor compreender a ideia de fusão que o autor propõe, faz-se necessário mencionar os três grandes modelos constitucionais que Gargarella (2013) reconhece: o republicano, o liberal e o conservador. O modelo republicano salientaria a questão do autogoverno. Envolta em uma linguagem e um ideário claramente rousseauneanos, a posição republicana teria cumprido um importante papel na luta pela universalização do sufrágio, além de ter deixado sua marca no debate acerca dos direitos constitucionais, cujo conteúdo fixa a vontade geral. O modelo constitucional conservador, por sua vez, fundamentar-se-ia na ideia de que a sociedade deve organizar-se em torno de um projeto moral compreensivo que articula a ordem social, promovendo uma particular concepção de bem (em geral referida à determinada religião); e defenderia, ainda, a centralização presidencialista do poder político. Por fim, o modelo liberal, erigido sobre o valor nuclear da proteção da autonomia individual, teria um duplo objetivo: o de equilibrar o poder e o de assegurar a neutralidade moral do Estado. As manifestações institucionais mais importantes do duplo compromisso liberal teriam se conformado: (1) na constituição de um rol de direitos fundamentais, invioláveis e incondicionais; e (2) na conformação de um sistema de freios e contrapesos, como medida de contenção tanto da concentração conservadora da autoridade política quanto da disposição republicana em converter a legislatura em órgão soberano.
} 
impulsionaram um esforço comum de redefinição crítica da teoria constitucional, em especial em face de sua tendência de uniformização sociocultural.

São experiências que podem oferecer recursos para que se aborde a questão que parece se constituir como o vetor contemporâneo das discussões no campo da cidadania: a tensão entre universalidade/igualdade (parâmetros de afirmação da cidadania moderna) e particularidade/diferença, que envolve o reconhecimento de novos direitos, a realização de políticas afirmativas, enfim, a emergência de um princípio de discriminação positiva.

Sob o pressuposto de que os critérios, os padrões e as balizas da justiça estão socialmente inscritos e se transformam historicamente - pois são estabelecidos na ação social de sujeitos que questionam os parâmetros intersubjetivos de reconhecimento e propõem alternativas a eles - coloca-se o desafio da permanente reconstrução da definição de justiça, o que demanda a participação dos atores sociais e o desenvolvimento de gramáticas morais capazes de considerar os outros como interlocutores (Mendonça e Marona, 2014).

A dimensão discursiva da justiça apontada por Tully (2004) empresta contornos discursivos, também, à Constituição, que passa a ser percebida em termos de um debate constitucional, atravessado pelas lutas sociais. A justiça e o debate constitucional tornam-se, assim, necessariamente dependentes da democracia, impondo a necessidade de democratizar/politizar os debates constitucionais, pela pressuposição da centralidade da dimensão política da justiça, considerando que o modo como as fronteiras da comunidade política são desenhadas pode implicar uma metainjustiça (Fraser, 2008), pois, na medida em que muitos sujeitos não podem participar desse delineamento, não têm as condições para vir a questionar injustiças e estão submetidos a uma forma de silenciamento ainda mais estrutural.

Questiona-se, nesse ponto, a tradicional função estabilizadora da Constituição, sob o pressuposto de que a estabilidade que, nos termos da teoria moderna é proporcionada pelo constitucionalismo, torna-se um brutal mecanismo de manutenção de exclusões estruturais, no âmbito de um projeto político projeto que assentou a ideia e a prática de uma cidadania profundamente excludente. Advoga-se, ao contrário, a possibilidade permanente de revisão democrática, ampla e plural da Constituição, como uma oportunidade de reconstrução dos frames da comunidade política.

Conforme apontado, o conceito de cidadania, que desde as suas origens está vinculado à ideia de pertencimento a determinada comunidade, modernamen- 
te, vinculou-se à narrativa do pacto social como momento fundacional da comunidade política. A cidadania moderna é, portanto, nacional territorialmente circunscrita. Indica a possibilidade de participação integral na comunidade política sob o pressuposto do reconhecimento de uma espécie de igualdade humana básica. O conceito de cidadania remete, portanto, à ideia de inclusão, a qual se estabelece em dois níveis: (1) ser cidadão é ser identificado como membro de uma nação particular e (2) ter direitos assegurados pelo Estado correspondente àquela nação. Idealmente, portanto, a cidadania moderna se constitui um uma dimensão jurídica, como um status - ser portador de direitos e obrigações (sujeito de direitos) -, com vistas à proteção de uma identidade compartilhada, que revela a dimensão identitária da cidadania.

Contudo, a emergência daquela identidade compartilhada (nacional, cívica) se deu pelo encobrimento das múltiplas identidades compartilhadas (étnicas ou de grupos) existentes no território. O cidadão (universal) foi o elemento necessário para a criação do povo (unificado), sujeito da nação (cívica), em nome da qual diferenças e especificidades viram-se frequentemente suprimidas (Mignolo, 2007). A desarticulação entre as dimensões jurídica e identitária da cidadania, em face da dinâmica societária e cultural atravessada por crescente heterogeneidade e diferenciação em termos de etnia, raça, gênero, gerações, religiões etc. (Ferrajoli, 2007), coloca a questão das possibilidades e dos limites da tradução dessa diversidade em direitos.

Os direitos de cidadania devem, nesses termos, ser capazes de compatibilizar universalismo e particularismo, mas a defesa de particularidades e o reconhecimento de especificidades não pode implicar a supressão das premissas igualitárias. Isso demanda, contudo, que se conformem debates constitucionais que: (a) expressem a diversidade sociocultural da comunidade política, desprendido de uma hierarquia única, universal e abstrata entre os saberes, dando preferência às formas de conhecimento que garantam a maior participação dos grupos sociais envolvidos na concepção, na execução, no controle e na fruição da intervenção que proporcionam no mundo real; (b) provoquem o diálogo entre as diversas formas de conhecimento e o seu enriquecimento mútuo, o que demanda um esforço de tradução intersocial e intercultural capaz de tornar possível a identificação de preocupações comuns, aproximações complementares e também contradições intransponíveis.

No Brasil, após 1985, com o fim da ditadura militar, os direitos civis foram restabelecidos; e, após 1988, com a promulgação da nova Constituição, os 
direitos políticos adquiriram uma amplitude nunca antes experimentada pelo povo brasileiro. Ademais, um amplo rol de direitos sociais foi consagrado constitucionalmente. Destaca-se, ainda, nesse processo de construção de um novo marco constitucional, a ampla participação da sociedade civil, o que induziu a ampliação do teor democrático do direito, pela determinação da obrigatoriedade da participação direta da sociedade civil na conformação de inúmeras políticas sociais. Nesse ponto, a Constituição brasileira de 1988 introduziu significativas mudanças, ampliando enormemente as formas de participação política. Em oito diferentes tópicos há alguma referência à participação popular: logo no art. $1^{\circ}$, que trata da soberania popular, mas também no art. 14, assumindo diferentes formatos (referendo ou iniciativa popular) e, ainda, em três capítulos dedicados às políticas sociais (saúde, assistência social e criança e adolescente) e naquele dedicado à política urbana e meio ambiente. A participação toma forma, ainda, pela previsão de audiências públicas conduzidas no interior do Legislativo.

A enorme autonomia do Poder Judiciário no novo quadro constitucional é, ainda, digna de nota. Por fim, deve-se referir que foi instituído um amplo sistema de controle de constitucionalidade das leis e atos normativos. $\mathrm{Na}$ Constituição brasileira há previsão de duas espécies de reforma: a revisão constitucional $\left(\mathrm{ADCT}, \text { art. } 3^{\circ}\right)^{14} \mathrm{e}$ a emenda à Constituição $(\mathrm{CRFB} / 88$, art. 59, I). Esta última caracteriza-se como a forma regular de alteração do texto constitucional, de competência do Congresso Nacional, limitada, entretanto, pelas cláusulas pétreas (a forma federativa de Estado; o voto direto, secreto, universal e periódico; a separação dos poderes e os direitos e garantias individuais) ${ }^{15}$. As emendas constitucionais devem ser elaboradas, portanto, respeitando inúmeras limitações. Além daquelas limitações materiais (conhecidas como

\footnotetext{
${ }^{14}$ A emenda constitucional de revisão, conforme o art $3^{\circ}$ do Ato das Disposições Constitucionais Transitórias (ADCT), além de possuir implicitamente as mesmas limitações materiais e circunstanciais e os mesmos sujeitos legitimados que o procedimento comum de emenda constitucional, também tinha limitação temporal - apenas uma revisão constitucional foi prevista, cinco anos após a promulgação, sendo realizada em 1993. No entanto, ao contrário das emendas comuns, ela tinha um procedimento de deliberação parlamentar mais simples para reformar o texto constitucional pela maioria absoluta dos parlamentares, em sessão unicameral e promulgação dada pela Mesa do Congresso Nacional.

15 Há, ainda, um terceiro tipo de normas com nível de emendas constitucionais. A Emenda Constitucional $n^{\circ} 45$, de 2004 , adicionou o $\S 3^{\circ}$ ao art. $5^{\circ}$ da Constituição, que dispõe que tratados e convenções internacionais de direitos humanos aprovados com o mesmo rito de aprovação de emendas constitucionais têm força de emendas, passando a fazer parte do rol de direitos fundamentais, que, por sua vez, têm caráter de cláusula pétrea e não podem ser derrogados. Logo, tais tratados não poderão ser denunciados, nem com aprovação do Congresso Nacional.
} 
cláusulas pétreas, art. $60, \S 4^{\circ}$ ), há limitações circunstanciais (art. $\left.60, \S 1^{\circ}\right)^{16}$, limitações formais ou procedimentais (art. 60, I, II, III, $₫ 3^{\circ}$ ), e ainda há uma forma definida de deliberação (art. $60, \S 2^{\circ}$ ) e promulgação (art. $\left.60, \S 3^{\circ}\right)^{17}$.

A Constituição brasileira já sofreu 72 emendas constitucionais e seis emendas de revisão constitucional, provenientes da única revisão constitucional geral prevista pela lei fundamental brasileira, que aconteceu em 5 de outubro de 1993. Assim, parece evidente que o padrão de mudança constitucional brasileiro é diferente do padrão liberal norte-americano de exclusão da soberania do processo de revisão constitucional. Uma parte grande das emendas constitucionais, no caso brasileiro, está ligada àquilo que Couto e Arantes (2006) denominaram de policy, isto é, de mudanças na organização das políticas públicas, com reflexos no âmbito de determinação do escopo e parâmetros da cidadania.

Por outro lado, a constitucionalização dos regimes políticos, que importa na incorporação de mecanismos de revisão judicial e controle de constitucionalidade das leis e atos normativos, chegou também ao Brasil induzido pela redemocratização (Hirschl, 2009), e, com ela, alterou-se o padrão de relação entre as tradicionais instituições políticas representativas e o Judiciário e/ou cortes constitucionais. No Brasil, o controle repressivo de constitucionalidade é feito por juízes e tribunais ${ }^{18}$ e se dá através de dois sistemas - difuso e concentrado - exercidos, respectivamente, por todos os integrantes do Poder Judiciário ${ }^{19}$ e pelo Supremo Tribunal Federal (STF) ${ }^{20}$.

${ }^{16}$ A Constituição proíbe seja emendada a Constituição vigorando intervenção federal, estado de defesa ou estado de sítio (CRFB/88, art. 60, § 2०).

17 Até se tornar uma emenda constitucional, o projeto toma o nome de Proposta de Emenda à Constituição (PEC), que pode ser proposta: por, no mínimo, (um terço) dos membros da Câmara dos Deputados ou do Senado Federal; pelo Presidente da República; ou por mais da metade das Assembleias Legislativas das unidades da Federação, manifestando-se, cada uma delas, pela maioria relativa (isto é, maioria simples) de seus membros. Proposta a PEC, ela deverá ser discutida e votada em cada Casa do Congresso Nacional, em dois turnos, alternadamente, e será aprovada se obtiver, em cada uma, aprovação de no mínimo três quintos dos votos dos respectivos membros, isto é, 308 deputados e 49 senadores. Obtendo o quorum, a emenda à Constituição será promulgada pelas Mesas da Câmara dos Deputados e do Senado Federal e entra em vigor 45 dias após sua publicação.

18 No Brasil, o controle de constitucionalidade pode ser exercido antes ou depois da aprovação do ato legislativo ou normativo: diz-se preventivo quando o controle é feito antes da elaboração da lei, pelo Poder Legislativo (via Comissão de Constituição e Justiça) ou Executivo (pelo veto presidencial), impedindo que um projeto de lei inconstitucional venha a ser promulgado; diz-se repressivo quando o controle é realizado pelo Poder Judiciário, após a elaboração da lei ou ato normativo, com a finalidade de retirar esses atos da esfera jurídica, dada sua incompatibilidade com a norma constitucional maior.

19 Nesse caso, o objeto da ação é a satisfação de um direito individual ou coletivo e a inconstitucionalidade do ato legislativo ou normativo é arguido incidentalmente por qualquer das partes, autor ou réu.

20 Nesse caso, o objeto da ação é a própria declaração da inconstitucionalidade do ato legislativo ou normativo, e a decisão proferida terá efeitos erga omnes (vale para todos), tornando-se a lei fulminada 
No caso do Brasil consolidou-se, portanto, um sistema híbrido de controle judicial de constitucionalidade bastante singular.

No interior desse sistema, o Supremo Tribunal Federal foi assumindo cada vez mais centralidade. Inspirado no modelo europeu, faz vezes de corte constitucional ao atuar no controle (concentrado) de constitucionalidade das leis, o que poderia situá-lo num ponto independente dos três poderes. Por outro lado, ao operar na revisão judicial, que remete à tradição norte-americana, o STF se inclui dentre os órgãos do Poder Judiciário com competências revisionais em matéria constitucional.

E nesse caso o STF só se destaca como guardião da Constituição pela força vinculante de suas decisões, geralmente em sede de Recurso Extraordinário ${ }^{21}$. Mesmo em sede de controle difuso de constitucionalidade, teoricamente mais descentralizado, a competência recursal do Supremo Tribunal Federal torna ainda mais nítida sua função de guardar e uniformizar a interpretação do texto constitucional, mormente depois das modificações introduzidas pela Emenda Constitucional no $45 / 2003^{22}$, ponto culminante do processo de reforma do Judiciário.

pela inconstitucionalidade, imediatamente inaplicável.

${ }^{21}$ Recursos extraordinários podem levar a questão constitucional até o STF, que, então, "atuará como órgão de cúpula do Judiciário e suas decisões valerão apenas para as partes concretamente envolvidas" (Arantes, 2013).

22 A Emenda Constitucional n 45/2004, a introduzir mudanças significativas na estrutura do Judiciário brasileiro, adotou inúmeras medidas centralizadoras do controle de constitucionalidade, as quais ampliaram o seu caráter rígido e altamente hierarquizado, praticamente excluindo os magistrados de instâncias inferiores da jurisdição sobre a Constituição e o direito constitucional. O judicial review ganhou novos contornos na medida em que se instituiu a súmula vinculante e a repercussão geral como requisito do recurso extraordinário. Com isso foram quase exclusivamente encaminhadas para o STF, órgão de cúpula do Poder Judiciário, as questões acerca da constitucionalidade das leis e atos normativos. O ainda possível controle difuso de constitucionalidade e, talvez de modo mais amplo, a possibilidade de os diversos juízos e tribunais inferiores construírem suas convicções acerca da constitucionalidade das leis e atos normativos foram golpeados pela súmula vinculante. Some-se a isso a alteração do sistema recursal, com a introdução do requisito da repercussão geral, a motivar a postura do STF de afirmar a tese da transcendência de motivos determinantes em sede de controle concentrado (em abstrato) de constitucionalidade (judicial review), concentrando ainda mais poder em seus domínios. A repercussão geral é um requisito de admissibilidade do recurso extraordinário, que funciona como um mecanismo de filtragem recursal, permitindo afastar do âmbito dos trabaIhos do STF as causas que são entendidas como de menor importância e cujo pronunciamento do tribunal não se justificaria. A decisão acerca da inexistência da repercussão geral vincula o próprio Tribunal - vinculação horizontal (art. 543-A, $\S 5^{\circ}$, do CPC) - e, nos processos com idêntica controvérsia, impõe vinculação vertical, na medida em que os Tribunais de origem represam os recursos e estes são considerados automaticamente não admitidos quando negada a existência da repercussão geral (art. 543-B, $\S 2^{\circ}$, do CPC). 
Pode-se dizer então, que a promulgação da Carta Magna de 1988 representou uma verdadeira refundação do Estado brasileiro, especialmente pela generalização da experiência do constitucionalismo democrático. No Brasil pós-88, mantiveram-se abertos os canais de reforma constitucional, com destaque para o amplo sistema de revisão judicial e controle de constitucionalidade das leis e atos normativos e para a centralidade do Supremo Tribunal Federal no interior desse sistema, o que conformou um padrão muito peculiar de judicialização da política.

\section{Judicialização da política no Brasil: o que é possível afirmar?}

A judicialização da política, que reflete o crescente envolvimento do Judiciário nos processos decisórios - especialmente no âmbito de conformação das políticas públicas - em democracias contemporâneas não é um fenômeno particularmente brasileiro. A ampliação da influência do direito no mundo contemporâneo sobre todas as dimensões da vida é um dado reconhecido por analistas de diversas partes do mundo (Tate e Vallinder, 1995; Santos et al., 1996; Garapon, 1999; Vianna et al., 1999), conformando rica e variada bibliografia, que reúne hipóteses acerca das causas e consequências do crescente protagonismo social e político dos tribunais.

Esse é um fenômeno que (re)coloca, dentre outras importantes questões, a do conteúdo democrático do intervencionismo judiciário. Isso porque o padrão de intervencionismo judiciário que o fenômeno capta por vezes pode se assentar em um entendimento ampliado do controle da legalidade que inclui "a reconstitucionalização do direito ordinário como meio de fundar um garantismo mais ousado dos direitos dos cidadãos" (Santos et al., 1996, p. 20), o que parece ser o caso do Brasil.

No âmbito de análise do fenômeno, um dos mais expressivos trabalhos apresentados (Vianna et al., 1999) aposta no peso de determinados fatores sociais na conformação de uma atuação de viés político do Judiciário, na linha de Cappelletti (1993) e Garapon (1999), para quem o movimento expansivo do direito deita raízes na sociedade civil e "vai encontrar sua institucionalização na ação parlamentar, não derivando (...) de veleidades ativistas originárias do poder judicial” (Vianna, 2013). A judicialização da política no Brasil assumiria uma feição singular ao trazer para dentro do Judiciário impulsos democratizantes oriundos da sociedade civil (Vianna, 2013). 
A relativização do poder soberano pode gerar, contudo, consequências em várias direções (Santos, 2003). Segundo Garapon (1999), o protagonismo dos tribunais é, de fato, um fenômeno de natureza social, mas remete ao esvaziamento dos ideais e práticas democráticas que faz substituir as modernas instituições associativas, induzindo deslocamentos de legitimidade. $\mathrm{O}$ protagonismo do Judiciário estaria, nesses termos, diretamente associado à generalizada desconfiança em relação às tradicionais instituições representativas; em especial, em relação aos Legislativos, permitindo assim tanto uma comunicação entre a sociedade civil e o Judiciário quanto uma forte limitação de impulsos democráticos pelo Poder Judiciário (Filgueiras e Marona, 2012). É possível perceber no caso do Brasil um movimento em ambas as direções.

A discussão acerca das vantagens ou desvantagens desse novo padrão de intereção entre os poderes conformou uma agenda de pesquisa que tende a atribuir sentido positivo ao que ora reconhece como transferência, ora como delegação de autoridade das instituições políticas representativas em direção ao Judiciário, captando o fenômeno no âmbito de um processo de aperfeiçoamento das democracias. Há divergências, contudo, bastante expressivas, as quais chegaram a cunhar o termo "juristocracia” (Vieira, 1994, 2008).

É possível observar, contudo, que na origem do fenômeno, em escala mundial, a partir da conhecida decisão da Suprema Corte Norte-Americana de 1803, não se vislumbra qualquer afirmação de superioridade do Poder Judiciário ou prerrogativa como instância política máxima. A história dos Estados Unidos disso dá testemunho tanto quando se consideram os conflitos entre os Poderes Judiciário e Executivo, que conduziram à Guerra Civil, como quando se tem em conta a reformatação da Suprema Corte durante o período do New Deal. Em ambos os casos a Suprema Corte se outorgou o papel de árbitro em última instância - da extensão dos direitos civis, no primeiro caso, e dos direitos sociais no segundo -, mas em ambas as situações restou intacto o papel do Executivo como estruturador de mudanças (Ackerman, 1988, p. 172). O Executivo acabou sendo o poder que levou à ampliação de direitos em ambos os momentos.

A tradição brasileira, diferentemente da norte-americana, não implicou de saída uma estrutura de equilíbrio de poderes. Até 1988 registrou-se uma fraca autonomia do Poder Judiciário, que, ao longo dos primeiros cem anos de República, não instituiu uma tradição de controle de constitucionalidade dos atos do Executivo, o qual se apresentou, desde logo, como o poder mais 
ativo, atuando em um contexto em que inexistiam garantias de contrapeso às suas prerrogativas.

Esse panorama foi alterado de modo radical a partir da Constituição de 1988, conforme já apontado. A Constituição não apenas instituiu o controle de constitucionalidade das leis e atos normativos (art. 102) como também passou a permitir que, além dos atores tradicionais do processo constitucional, a OAB e as entidades da sociedade civil passassem a intervir no processo de controle judicial de constitucionalidade ${ }^{23}$. Esse movimento institucional não apenas aponta na direção de uma situação de reequilíbrio entre os poderes, como também na reabertura dos canais de comunicação entre o Estado e a sociedade civil.

Ademais, vislumbra-se um movimento de democratização do processo de conformação do escopo dos direitos de cidadania, sem que, contudo, se chegue a vislumbrar a conformação de um debate constitucional que complexifique os contornos da comunidade política. Esse, portanto, não é um processo livre de contradições. A expressiva atuação dos partidos políticos no âmbito do controle judicial de constitucionalidade ${ }^{24}$ possui caráter marcadamente estratégico, conformando mera extensão dos embates congressuais (Taylor e Da Ros, 2007).

Matérias que, em princípio, seriam tipicamente da alçada deliberativa do Legislativo, tais como a reforma política - exemplarmente as questões referentes à cláusula de barreira e à disciplina partidária - ou até mesmo questões procedimentais internas ao Congresso Nacional, têm sido, frequentemente, decididas pelo Supremo Tribunal Federal. Nesse sentido, o Congresso Nacional precisa reassumir suas prerrogativas no que diz respeito à organização de governos representativos, promovendo reformas institucionais que restabeleçam a credibilidade do sistema de representação, pela criação de mecanismos que permitam assegurar a pluralização de representantes políticos formais, contestando a sub-representação tradicional de grupos excluídos e/ou minoritários (povos indígenas e comunidades tradicionais, mulheres e negros/as).

${ }^{23}$ Uma pesquisa coordenada pelo Observatório da Justiça Brasileira e executada pela Sociedade Brasileira de Direito Público mostrou que, de pouco mais de 800 dos Atos Declaratórios Interpretativos (ADIs), mais de 300 têm origem nas associações civis e sindicatos (Sunfield, 2011).

${ }^{24}$ Em pesquisa executada pela Sociedade Brasileira de Direito Público para o Observatório da Justiça Brasileira, mostrou-se que os partidos políticos acionaram o Supremo em 344 casos desde 1988 (Sunfield, 2011, p. 28). 
O reconhecimento da contingência da ideia de direitos e da definição de cidadania demanda a possibilidade da sua permanente e democrática revisão, o que é realizado, em grande medida, no âmbito dos debates constitucionais, os quais devem expressar a diversidade sociocultural da comunidade política, desprendidos de uma hierarquia única, universal e abstrata entre os saberes, dando preferência às formas de conhecimento que garantam a maior participação dos grupos sociais envolvidos na concepção, na execução, no controle e na fruição da intervenção que proporcionam no mundo real.

Esse parece ser o desafio que se coloca hoje, diante da judicialização da política no Brasil: a da ampliação da dimensão representativa, com destaque para a atuação dos movimentos sociais, especialmente no âmbito do debate constitucional, por um lado, e do fortalecimento da representatividade política do Judiciário, por outro. É notável, nesse tocante, a inclusão de mecanismos de participação ampliada nos processos de reconstitucionalização de diversos países latino-americanos, de que são exemplos as emendas populares no Brasil e mais recentemente os plebiscitos e referendos realizados no Equador e na Bolívia, ademais dos mais variados mecanismos de ampliação da representação e participação de atores sociais no âmbito do controle de constitucionalidade, com destaque para as audiências públicas no Supremo Tribunal Federal, no Brasil, ou para as regras de recrutamento dos juízes nas Cortes Constitucionais em países andinos.

\section{Conclusão}

A trajetória do processo de judicialização no Brasil nos permite afirmar mais claramente a existência no país de um modelo mais soberano e deliberativo, em contraste com o modelo norte-americano, que seria mais liberal e menos pautado pela soberania. Nesse sentido, são dois os avanços que propomos em relação a análises anteriores como a de Werneck Vianna et al. (1999), Maciel e Koerner (2002) e Couto e Arantes (2006): em primeiro lugar, o elemento soberano do processo de emenda constitucional é fundamental para a adaptação do constitucionalismo a novos contextos políticos; em segundo lugar, a questão fundamental não é a presença de corpos jurídicos mais próximos da sociedade civil e sim uma flexibilidade em torno ao processo de emendas que permite que o sistema político tenha um papel na adaptação do constitucionalismo ao contexto político. 
Assim, o caso brasileiro aponta em duas direções complementares: de um lado, o processo de elaboração de emendas constitucionais foi muito intenso nestes últimos 25 anos, mas não desconfigurou a armação constitucional básica no que diz respeito aos direitos e à divisão de poderes. Assim, a Constituição foi se adaptando a mudanças nas políticas que ela não previu e ajustando pontualmente a relação entre os poderes.

Por outro lado, no que diz respeito ao processo de revisão constitucional, houve uma fortíssima ampliação deste instituto nos últimos 25 anos. Os artigos 102 e 103 permitiram que o STF adquirisse prerrogativas fortíssimas na revisão constitucional de ações do Executivo e principalmente se posicionasse em relação a um conjunto de legislações propostas pelo Congresso Nacional. Dessa maneira, o Brasil começou a seguir um caminho de ampliação de direitos por meio de decisões judiciais, como foi o caso dos direitos dos povos indígenas, da ação afirmativa e da união homoafetiva. No entanto, o processo de judicialização também implicou a apropriação de fortes prerrogativas soberanas do Congresso em ações que definiram a derrubada da cláusula de barreira, a fidelidade partidária e, mais recentemente, regras da competição eleitoral. Algumas dessas ações ajudaram a organizar o sistema político ao passo que outras contribuíram para a continuidade da sua desorganização. Entretanto, independentemente do mérito dessas ações, elas implicaram fortes desequilíbrios entre os poderes, que podem afetar a democracia brasileira em um futuro próximo.

Assim, duas metas parecem desejáveis no médio prazo. Em primeiro lugar, que o Brasil continue o seu processo de rever a Constituição tanto pela via judicial quanto pela via da soberania, mas que os limites da soberania dos outros poderes sejam mais claramente estabelecidos. Em segundo lugar, parece importante que o Judiciário se conecte mais com a sociedade civil. Os processos deliberativos oriundos da sociedade civil devem afetar desde a nomeação de ministros do Supremo até a realização das audiências públicas, as quais devem ser frequentadas por todos os ministros. Dessa forma, uma conexão mais clara do próprio Judiciário com a soberania popular poderá oferecer a ele a legitimidade necessária para que o objetivo de um processo de ampliação de direitos torne-se uma realidade no país. 


\section{Referências}

ACKERMAN, Bruce (1988). “Neo-federalism”, em ELSTER, Jon \& SLAGSTADT, Run (eds.). Constitutionalism and democracy. Cambridge: Cambridge University Press.

ACKERMAN, Bruce (1993). We, the people. Cambridge (MA): The Belknap Press of Harvard University Press.

ARANTES, Rogério (2013). “Cortes constitucionais”, em AVRITZER, Leonardo et al. (orgs.). Dimensões políticas da justiça. Rio de Janeiro: Civilização Brasileira.

ARENDT, Hannah (1965). On revolution. Nova York: Penguin.

AVRITZER, Leonardo (2012). "O novo constitucionalismo latino-americano: uma abordagem política”, em II Seminário de Pesquisa: O Novo Constitucionalismo Democrático Latino-Americano, Santa Cruz de La Sierra, Bolívia.

CAPPELLETTI, Mauro (1993). Juizes legisladores? Porto Alegre: Sergio Antonio Fabris Editor.

CARVALHO NETO, Ernani (2004). “Em busca da judicialização da política no Brasil: apontamentos para uma nova abordagem”. Revista de Sociologia e Política, n. 23, p. 127-39.

(2007). "Revisão judicial e judicialização da política no direito ocidental: aspecto relevantes de sua gênese e desenvolvimento". Revista de Sociologia e Política, n. 28, p. 161-79.

(2008). "Dimensão política do acesso à justiça: aspectos da revisão judicial”, em GOMES NETO, José Mario Wanderley (org.). Dimensões do acesso à Justiça. Salvador: Jus Podivm.

(2009). "Judicialização da política no Brasil: controle de constitucionalidade e racionalidade política”. Análise Social, v. 44, p. 315-35.

(2010). “Trajetória da revisão judicial no desenho constitucional brasileiro: tutela, autonomia e judicialização”. Sociologias, n. 23, p. 176-207.

(2013). "O poder dos juízes: Supremo Tribunal Federal e o desenho institucional do Conselho Nacional de Justiça”. Revista de Sociologia e Política, v. 21, n. 45, p. 13-27.

CARVALHO NETO, Ernani \& TOMIO, Fabrício (2013). "Dossiê política, 
direito e judiciário: uma introdução". Revista de Sociologia e Política, v. 21, n. 45, p. $7-11$.

COSTA, Sérgio \& WERLE, Denilson Luís (2000). "Reconhecer as diferenças: liberais, comunitaristas e as relações raciais no Brasil”, em AVRITZER, Leonardo \& DOMINGUES, José Maurício (orgs.). Teoria social e modernidade no Brasil. Belo Horizonte: Editora UFMG.

COUTO, Cláudio Gonçalves \& ARANTES, Rogério Bastos (2006). "Constituição, governo e democracia no Brasil". Revista Brasileira de Ciências Sociais, v. 21, n. 61, p. 41-62.

DE VITA, Alvaro (2013). "Liberalismo contemporâneo", em AVRITZER, Leonardo et al. (orgs.). Dimensões políticas da justiça. Rio de Janeiro: Civilização Brasileira.

DWORKIN, Ronald (2001). Uma questão de princípio. Tradução de Luís Carlos Borges. São Paulo: Martins Fontes.

(2007). O império do direito. Tradução de Jefferson Luiz Camargo. São Paulo: Martins Fontes.

(2010). Levando os direitos a sério. São Paulo: Martins Fontes.

ELSTER, Jon \& SLAGSTADT, Run (1988). Constitutionalism and democracy. Cambridge: Cambridge University Press.

ELY, John (1980). Democracy and distrust. Cambridge: Harvard University Press.

ENGELMANN, Fabiano (2003). “A politização do direito no Brasil: caminhos para o estudo das novas relações entre Estado, cidadania e direito numa sociedade democrática”, em CAMERINI, Fabrizio \& MEZZANOTI, Gabriela (orgs.). Para pensar o direito. Novo Hamburgo: Editora Feevale. (2004). "Cidadania e efetivação de direitos no Brasil: caminhos e perspectivas”, em MARTINS, Rodrigo P. \& Machado, Carlos R. S. (orgs.). Conceitos, movimentos e identidades: fundamentos para discussão da realidade brasileira. Novo Hamburgo: Editora Feevale.

(2007). "Tradition and diversification in the uses and definitions of the law: a proposed analysis". Brazilian Political Science Review, v. 1, n. 1, p. 53-70.

(2008). "La reforma judicial en Brasil: la movilización de los juristas”, em SANTAMARIA, Angela \& VECCHIOLI, Virginia (orgs.). Derechos humanos en América latina: mundialización y circulación internacional del conociemento experto jurídico. Bogotá: Universidad del 
Rosario; Centro de Estúdios Políticos Internationales.

(2011). "Politização e instituições judiciais no Brasil após a Constituição de 1988”. In: MOTA, Maurício; MOTA, Luiz Eduardo (orgs.). O Estado democrático de direito em questão. Rio de Janeiro: Elsevier. ENGELMANN, Fabiano \& CUNHA FILHO, Márcio Camargo (2013). "Ações judiciais, conteúdos políticos: uma proposta de análise para o caso brasileiro". Revista de Sociologia e Política, v. 21, n. 45, p. 57-72.

FERRAJOLI, Luigi (2007). A soberania no mundo moderno: nascimento e crise do Estado nacional. Tradução de Carlo Coccioli \& Márcio Lauria. São Paulo: Martins Fontes.

FILGUEIRAS, Fernando \& MARONA, Marjorie (2012). “A corrupção, o judiciário e a cultura política no Brasil democrático", em BIASON, Rita de Cássia (org.). Temas de corrupção política. São Paulo: Balão Editorial. FRASER, Nancy (2008). Scales of justice: reimagining political space in a globalizing world. New York: Columbia University Press.

GARAPON, Antoine (1999). O juiz e a democracia: o guardião das promessas. Rio de Janeiro: Revan.

GARGARELLA, Roberto (2013). Latin American constitutionalism, 1810-2010: the engine room of the Constitution. Oxford: Oxford University Press.

GARGARELLA, Roberto \& COURTIS, Christian (2009). El nuevo constitucionalismo latinoamericano: promesas y interogantes. Santiago do Chile: CEPAL.

GRIJALVA, Agustín (2008). "El Estado plurinacional e intercultural en la constitución ecuatoriana del 2008”. Equador Debate, n. 75, p. 49-62.

HIRSCHL, Ran (2009). Towards juristocracy: the origins and consequences of the new constitutionalism. Harvard University Press.

HOLMES, Stephen (1988). "Precomitment and the paradox of democracy", em ELSTER, Jon \& SLAGSTADT, Run. Constitutionalism and democracy. Cambridge: Cambridge University Press.

HONNETH, Axel (2003). Luta por reconhecimento: a gramática moral dos conflitos sociais. Tradução de Luiz Repa. São Paulo: 34.

MACIEL, Débora Alves \& KOERNER, Andrei (2002). "Sentidos da judicialização da política: duas análises”. Lua Nova, n. 57, p. 113-33.

MARSHALL, Timothy Humphrey (1967). Cidadania, classe social e status. Rio de Janeiro: Zahar. 
MENDONÇA, Ricardo F. (2013). "Reconhecimento”, em AVRITZER, Leonardo et al. (orgs.) Dimensões políticas da justiça. Rio de Janeiro: Civilização Brasileira.

MENDONÇA, Ricardo F. \& MARONA, Marjorie C. (2014) "O novo constitucionalismo e a teoria do reconhecimento: aproximações possíveis", em LAVALLE, Adrian Gurza; DE VITA, Alvaro \& ARAUJO, Cícero (orgs.). O papel da teoria política contemporânea: justiça, Constituição, democracia e representação. São Paulo: Alameda Editorial, no prelo.

MIGNOLO, Walter (2007). La idea de América Latina: la herida colonial y la opción decolonial. Barcelona: Gedisa Editorial S.A.

NOBRE, Marcos (2008). "Indeterminação e estabilidade: os 20 anos da Constituição Federal e as tarefas da pesquisa em direito". Novos Estudos CEBRAP, n. 82, p. 97-106.

(2011). "Apontamentos sobre a pesquisa em direito no Brasil”, em FABIANI, Emerson Ribeiro (org.). Impasses e aporias do direito contemporâneo: estudos em homenagem a José Eduardo Faria. São Paulo: Saraiva. OLIVEIRA, Vanessa Elias de (2005). "Judiciário e privatizações no Brasil: existe uma judicialização da política?”. Dados, v. 48, n. 3, p. 559-87.

OSTRENSKY, Eunice (2013). "Liberalismo clássico", em AVRITZER, Leonardo et al. (orgs.). Dimensões políticas da justiça. Rio de Janeiro: Civilização Brasileira.

REHFELD, Andrew (2005). The concept of constituency. Cambridge: Cambridge University Press.

REIS, Fábio Wanderlei \& O’DONNELL, Guillermo (orgs.) (1988). A democracia no Brasil: dilemas e perspectivas. São Paulo: Vértice.

RODRIGUEZ, José Rodrigo (2010a). "Inverter o espelho: o direito ocidental em normatividades plurais”, em REIS, Rossana Rocha (org.). Política de direitos humanos. São Paulo: Editora Hucitec.

(2010b). "The persistence of formalism: towards a situated critique beyond the classic separation of powers". The Law and Development Review, v. 3, n. 2, p. 41-77.

(2013). Como decidem as cortes: para uma crítica do direito brasileiro. Rio de Janeiro: Editora FGV.

SANTOS, Boaventura de Sousa (2003). Reconhecer para libertar: os caminhos do cosmopolitismo multicultural. Rio de Janeiro: Civilização Brasileira. (2010). Refundacion del Estado en América Latina: perspectivas 
desde una epistemologia del sur. Lima: Instituto Internacional de Derecho y Sociedade.

SANTOS, Boaventura de Sousa et al. (1996). Os tribunais na sociedade contemporânea. Porto: Afrontamento.

SIEDER, Rachel (2002). Multiculturalism in Latin America: indigenous rights, diversity and democracy. London: Palgrave; ILAS.

SUNFIELD, Carlos Ari et al. (2011). Controle de constitucionalidade e judicialização: o STF frente à sociedade e aos poderes. Belo Horizonte: Observatório da Justiça Brasileira.

TAPIA, Luis (2007). "Una reflexión sobre la idea de Estado plurinacional". OSAL, ano 8, n. 22, p. 47-63.

TATE, C. Neal \& VALLINDER, Torbjörn (1995). The global expansion of judicial power. Nova York: New York University Press.

TAYLOR, Matthew M. \& DA ROS, Luciano (2007). “O Judiciário e as políticas públicas no Brasil”. Dados, v. 50, n. 2, p. 229-57.

TULLY, James (2004). "Recognition and dialogue: the emergence of a new field”. Critical Review of International Social and Political Philosophy, v. 7, n. 3, p. 84-106.

VIANNA, Luiz Werneck (2013). “A judicialização da política”, em AVRITZER, Leonardo et al. (orgs.). Dimensões políticas da justiça. Rio de Janeiro: Civilização Brasileira.

VIANNA, Luiz Werneck et al. (1999). A judicialização da política e das relações sociais no Brasil. Rio de Janeiro: Revan.

VIANNA, Luiz Werneck; BURGOS, Marcelo \& SALLES, Paula (2007). "Dezessete anos de judicialização da política". Tempo Social, v. 12, n. 2, p. 39-85.

VICIANO PASTOR, Roberto \& MARTINEZ DALMAU, Rubén (2005). "El proceso constituyente venezolano en el marco del nuevo constitucionalismo latino-americano". Agora, n. 13, p. 55-68.

(2010). "Aspectos generales del nuevo constitucionalismo latinoamericano". Corte constitucional del Equador para el período de transiocion: el nuevo constitucionalismo latinoameticano. Quito: Corte Constitucional del Equador.

VIEIRA, Oscar Vilhena (1994). "Império da lei ou da corte?". Revista USP, n. 21, p. $70-7$.

(2008). “Supremocracy”. Revista Direito GV, v. 4, n. 2, p. 441-63. 
YRIGOYEN FAJARDO, Raquel (2006). "Hitos del reconocimiento del pluralismo jurídico y el derecho indígena en las políticas indigenistas y el constitucionalismo andino", em BERRAONDO, Mikel (coord.). Pueblos indígenas y derechos humanos. Bilbao: Universidad de Deusto. (2009). "Aos 20 anos do convênio da OIT: balanço e desafios da implementação dos direitos dos povos indígenas na América Latina”, em VERDUM, Ricardo. Povos indígenas: constituições e reformas políticas na América Latina. Brasília: Instituto de Estudos Socioeconômicos.

\section{Resumo}

O presente trabalho busca abordar o fenômeno da judicialização da política no Brasil a partir de uma perspectiva analítica que supere o marco liberal. Parte-se do pressuposto de que as versões acerca da judicialização da política são construídas a partir de uma perspectiva comum, forjada sob os auspícios das teorias democrática e constitucional hegemônicas. No entanto, a realidade histórico-constitucional brasileira - nomeadamente após a redemocratização - é inovadora não apenas do ponto de vista institucional, como também enseja a renovação dos termos da relação entre sociedade civil e Estado na conformação do sistema político, emprestando novos contornos ao fenômeno da judicialização da política.

Palavras-chave: constitucionalismo, democracia, liberalismo, judicialização, Poder Judiciário.

\section{Abstract}

This paper seeks to address the phenomenon of judicialization of politics in Brazil from an analytical perspective that overcomes the liberal framework. It assumes that views on judicialization of politics are built from a common perspective, forged under the auspices of democratic and constitutional hegemonic theories. However, the Brazilian historical and constitutional reality - particularly after democratization - is innovative not only from the institutional point of view, but also because it entails the renewal of the terms for the relationship between civil society and State in shaping the political system, lending new shape to the phenomenon of judicialization of politics.

Keywords: constitutionalism, democracy, liberalism, judicialization, Judiciary.

Recebido em 18 de novembro de 2013.

Aprovado em 18 de julho de 2014. 